\title{
Comparison of Four Methods for Vertical Extrapolation of Soil Moisture Contents from Surface to Deep Layers in an Alpine Area
}

\author{
Jinlin $\mathrm{Li}^{1, *}$ and Lanhui Zhang ${ }^{2}$ (1) \\ 1 College of Geography and Environmental Science, Northwest Normal University, Lanzhou 730070, China \\ 2 Key Laboratory of West China's Environmental System (Ministry of Education), College of Earth and \\ Environmental Sciences, Lanzhou University, Lanzhou 730000, China; lhzhang@lzu.edu.cn \\ * Correspondence: lijinlin@nwnu.edu.cn
}

Citation: Li, J.; Zhang, L.

Comparison of Four Methods for

Vertical Extrapolation of Soil Moisture Contents from Surface to Deep Layers in an Alpine Area. Sustainability 2021, 13, 8862. https://doi.org/10.3390/ su13168862

Academic Editor: Matteo Convertino

Received: 4 July 2021

Accepted: 5 August 2021

Published: 8 August 2021

Publisher's Note: MDPI stays neutral with regard to jurisdictional claims in published maps and institutional affiliations.

Copyright: (C) 2021 by the authors. Licensee MDPI, Basel, Switzerland. This article is an open access article distributed under the terms and conditions of the Creative Commons Attribution (CC BY) license (https:// creativecommons.org/licenses/by/ $4.0 /)$.

\begin{abstract}
The accurate estimation of moisture content in deep soil layers is usually difficult due to the associated costs, strong spatiotemporal variability, and nonlinear relationship between surface and deep moisture content, especially in alpine areas (where complications include extreme heterogeneity and freeze-thaw processes). In an effort to identify the optimal method for this purpose, this study used measurements of soil moisture content at three depths $(4,10$, and $20 \mathrm{~cm})$ in the upper parts of the Babao River basin in the Qilian Mountains, Northwest China. These measurements were collected in the HiWATER (Heihe watershed allied telemetry experimental research) program to test four vertical extrapolation methods: exponential filtering (ExpF), linear regression (LR), support vector regression (SVR), and the application of a type of artificial neural network, the radial basis function (RBF). SVR provided the best predictions, in terms of the lowest root mean squared error and mean absolute error values, for the 10 and $20 \mathrm{~cm}$ layers from surface layer $(4 \mathrm{~cm})$ measurements. However, the data also confirmed that freeze-thawing is an important process in the study area, which makes the infiltration process more complex and highly variable over time. Thus, we compared the vertical extrapolation methods' performance in each of the four periods with differing infiltration characteristics and found significant among-period differences in each case. However, SVR consistently provided the best estimates, and all methods provided better estimates for the $10 \mathrm{~cm}$ layer than for the $20 \mathrm{~cm}$ layer.
\end{abstract}

Keywords: soil moisture; vertical extrapolation methods; alpine mountainous area; freeze-thaw; support vector regression; exponential filter

\section{Introduction}

Soil moisture plays a crucial climatic role, particularly in water and energy exchanges between land surfaces and the atmosphere [1-3], in a myriad of environmental and ecological processes [4]. Inter alia, it strongly affects the distribution of precipitation by modulating processes including runoff, infiltration and surface storage, plant growth, and microbial population dynamics [5]. Thus, accurate monitoring or prediction of soil moisture content (SMC), especially in deep soil layers, is essential in land and agricultural management [6-10], especially in any area where it is not reliably abundant. However, this is far from straightforward, because SMC is affected by numerous factors, including soil properties, climate, land cover, and both biophysical and topographical surface characteristics, especially at large scale, hence it is highly variable in space and time [11-13].

There are many robust ways to collect surface soil moisture data, including through the use of portable sensors, cosmic-ray neutron probes, and ground-penetrating radar for fine-scale measurements $[14,15]$, and various remote sensing techniques for larger-scale measurements $[16,17]$. Monitoring networks can also provide accurate, simultaneous, in situ measurements of soil moisture at different depths, which can be compiled in databases, such as the North American Soil Moisture Database [5,18]. However, this requires major 
investments in manpower and equipment, field and laboratory work, and such networks have significant limitations in terms of spatial extent and resolution [9,11]. Moreover, establishing and maintaining them is difficult, especially in areas with high elevations and steep slopes $[19,20]$. Thus, methods for estimating moisture content in deep soil layers from the vertical extrapolation of surface layer values are receiving increasing attention.

There are many methods, based on various theories, for extrapolating SMC in deep layers from surface SMC measurements. These include assimilation of remote sensing data into land surface models [21,22], and physically-based approaches constrained by required parameters in terms of soil properties, vegetation features, and atmospheric forcing [23-27]. Other approaches involve the use of empirical relationships between the evaporative fraction and soil moisture [28], correlations with vegetation [29], a semi-empirical exponential filter $(\mathrm{ExpF})$ [30], or a data-driven artificial neural network (ANN) [31]. Empirical modelling is onerous because of the need to collect large amounts of data to cover the great variability that the models must account for [24,32,33]. In contrast, theoretical models often use simple relationships, but they may not be reliable paradigms for the real world $[9,34,35]$. However, although they are usually less accurate than empirical models, and may lack physical realism [5], researchers are still interested in theoretical methods for predicting SMC profiles because of their convenience and potential applicability in diverse environments. Moreover, although data-driven methods are useful for identifying patterns in existing datasets, they may not provide good estimates for environments with conditions that differ substantially from training sets. In attempts to handle the high complexities and variabilities involved, and obtain accurate SMC models, various machine learning techniques, such as random forest and support vector machine (SVM) algorithms, have been used recently [36-38]. The machine learning techniques can overcome partial convergence problems associated with ANNs because they require less complex parameter selection and have a higher ability to find global optimal solutions [39]. They have exhibited better performance than ANNs in hydrological applications by producing smaller errors and stronger correlation [40-43]. However, few studies have applied machine learning techniques to the extrapolation of SMC from surface to deep layers, particularly in alpine areas. Therefore, this study assessed four commonly used methods, linear regression (LR), exponential filtering (ExpF), ANNs, and a machine learning technique (SVR), to identify the most suitable approach for operational estimation of SMC at different depths. Each method has specific strengths and weaknesses, but any method with operational utility must clearly have the substantial ability to handle the nonlinear relationship between surface and deep SMC, and extreme variability in factors affecting SMC in alpine environments. The alpine areas are the birthplace of the major rivers in China. Its ecological environment is extremely fragile and sensitive to the climate change [44]. The freeze thaw process directly affects basin runoff and is the most important research content in alpine areas [20]. This area has high elevations, steep slopes, and complex terrain, with large variations in soil properties, climate, land cover, and both biophysical and topographical surface characteristics [45]. Use of traditional methods for soil moisture measurements (e.g., gravimetric, time domain reflectometry (TDR), and neutron probe methods) is extremely difficult in this region $[19,20]$. Therefore, this study focused on part of a large alpine region in northwest China.

Freeze-thawing is an important hydrological process in this region and is strongly related to seasonal variation [46-48]. The accompanying phase changes in soil moisture significantly affect land surface water and energy budgets [49-51]. Thus, freeze-thawing strongly influences soil moisture variance. Moreover, spring soil moisture anomalies, caused by the thawing of frozen soils and melting of snow, strongly affect summer precipitation in East Asian [52,53]. Studies regarding effects of spring soil moisture on subsequent summer precipitation [54-57] have focused on spring diabatic heating. However, soil moisture anomalies prior to spring also putatively affect summer climate. The mechanism can be explained as follows: the longer soil frozen periods, the more soil moisture anomalies can persist up to spring and favor the wetter anomalies of spring soil moisture $[48,58]$. 
Thus, there are clear needs to understand distributions of SMC in the focal area, and to develop robust vertical extrapolation methods for estimating the moisture contents of deep soil layers from the contents in surface layers.

\section{Study Area and Datasets}

\subsection{Study Area}

The study area consisted of the upper part of the basin of the Babao River, a tributary of the Heihe River, in Northwest China [59]. The basin has an area of $2450 \mathrm{~km}^{2}$ (latitude $37^{\circ} 43^{\prime}-$ $38^{\circ} 20^{\prime} \mathrm{N}$, longitude $100^{\circ} 05^{\prime}-101^{\circ} 09^{\prime} \mathrm{E}$ ), with an elevation ranging from 2339 to $4947 \mathrm{~m}$, and an annual average temperature of $-1{ }^{\circ} \mathrm{C}$. The local climate can be characterized as semiarid and alpine cold, with the $300-500 \mathrm{~mm}$ annual precipitation associated with the southwest monsoon. Both temperature and precipitation vary significantly with elevation because of the steep topography and large variation in elevation [60]. The mean annual precipitation increases from about $250 \mathrm{~mm}$ in the low-mountain or hill zone to about $500 \mathrm{~mm}$ in the high-mountain zone, which has an elevation ranging from 2000 to $5500 \mathrm{~m}$ a.s.1. [60]. The altitudinal spring temperature lapse rate is $-0.48{ }^{\circ} \mathrm{C} / 100 \mathrm{~m}$ and altitudinal summer temperature is about $-0.46{ }^{\circ} \mathrm{C} / 100 \mathrm{~m}$ [61]. Vegetation in the basin is predominately mountain forest and grassland, with extensive shrub meadow coverage. Due to the high variations in climate (including temperature and precipitation), topography, vegetation cover, SMC and other pedological variables, there is remarkable spatial heterogeneity in ecohydrological parameters of the Babao River basin [62]. Clearly, this heterogeneity must be thoroughly addressed to describe the ecohydrological processes and interactions adequately. To assist such description, there are four national meteorological stations in or near the Babao watershed. In addition, a program called HiWATER (http:/ / westdc. westgis.ac.cn/) [59], including a "Waternet" (wireless sensor network for monitoring soil moisture, land surface temperature, and precipitation), was established to observe changes in important hydrological factors in the area [63]. Positions of the Waternet points and the meteorological station in the study area are shown in Figure 1.

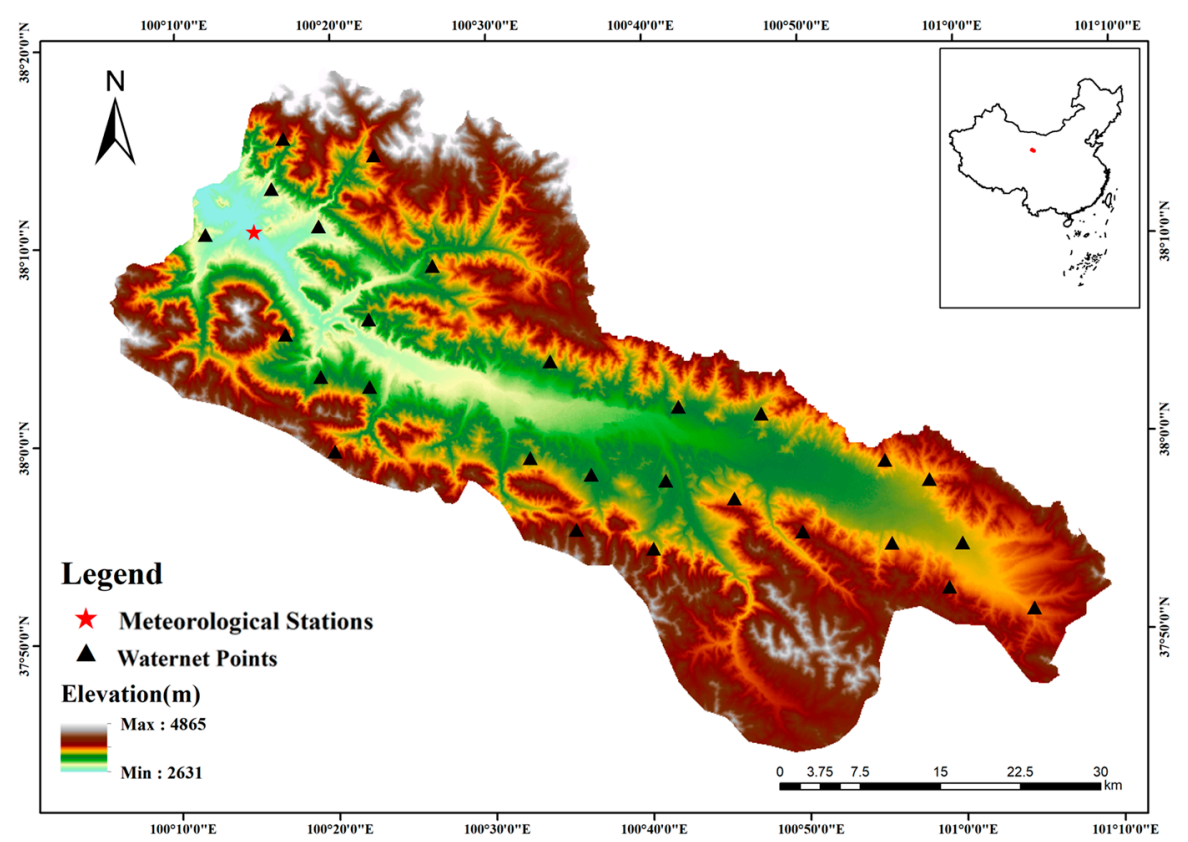

Figure 1. Digital elevation model (DEM) and positions of Waternet points and meteorological stations in the study area.

\subsection{Datasets}

Soil moisture and temperature data have been collected through the 40 Waternet points distributed in the Babao watershed [63], at a $5 \mathrm{~min}$ frequency and at three depths 
$(4,10$, and $20 \mathrm{~cm})$, using Hydra Probe II sensors (Stevens Water Monitoring System, Inc., Portland, OR, USA), since 30 June 2013. Many data points are missing, due to sensors being lost, damaged, or lacking power. Thus, 27 of the Waternet points were used and the temporal scale used in this study was daily (from 1 August 2013 to 12 September 2014). Here, the soil moisture is the volumetric moisture content of unfrozen soil, measured in $\mathrm{cm}^{3} / \mathrm{cm}^{3}$. Daily precipitation records were obtained from the four national meteorological stations: one is Qilian in the study area, and three others (Minle, Tuole, and Yeniugou) locate around the study area.

\section{Methods}

\subsection{Exponential Filtering (ExpF)}

Exponential filtering $(\operatorname{ExpF})$ is a semi-empirical method, initially derived from a simple water balance equation [30] and subsequently presented in a recursive form [64] in the following equations:

$$
\begin{gathered}
S M_{t_{n}}=S M_{t_{n-1}}+K_{n}\left(x_{n}-S M_{t_{n-1}}\right) \\
K_{n}=K_{n-1} /\left[K_{n-1}+\exp (-1 / T)\right]
\end{gathered}
$$

where $T$ is the optimal characteristic decay time, $S M_{t_{n}}\left(\mathrm{~cm}^{3} / \mathrm{cm}^{3}\right)$ is the SMC in a focal deep layer at time $t_{n}$, and $x_{n}$ is the surface soil moisture at time $t_{n}$. As previously noted, $T$ is insensitive to many factors [5]. In this study, the optimal $T$ value was found by minimizing root mean squared error (RMSE) and mean absolute error (MAE) at each depth. The results are shown in Section 4.1.1.

\subsection{Support Vector Regression (SVR)}

SVR is used in SVM learning to solve complex regression problems [65]. This method involves structural risk minimization to minimize empirical risk (performance on a known set of training data), which is the general aim of statistical learning systems, such as ANNs [66]. However, structural risk reduction involves the minimization of empirical risk to obtain good generalization capacity by minimizing the error of the generalization rather than the training error $[41,67]$. Fundamentally, SVR involves nonlinear mapping of primary data into a higher-dimensional feature space and the use of a kernel function for linear regression in the feature space [41,68-70]. Several types of kernels can be used (e.g., polynomial, linear, or sigmoid), but the RBF reportedly provides the best performance [71-74]. To identify the optimal choice in this study, we compared the performance of SVR with several kernels. The results are shown in Section 4.1.2.

\subsection{Radial Basis Function (RBF)}

ANNs have received a great deal of attention in recent years due to their ability to overcome non-linearity and multicollinearity problems, and numerous types have been developed [75-79]. The RBF is a multi-layer feed-forward ANN. The architecture and training algorithms of RBF networks are simpler and clearer than back-propagation networks $[80,81]$. Furthermore, they can be trained more quickly than a multilayer perceptron network [82]. Thus, in this study, the RBF was selected as a representative form of ANN. It typically has a feed-forward structure with three layers: the input layer, hide layer (a non-linear RBF activation function), and linear output layer. Each layer may have one or more neural elements. This type of network has self-organizing characteristics that allow adaptive determination of the hidden neurons during training of the network [83]. Each input neuron is connected to all hidden neurons, and both hidden and output neurons are interconnected by a set of weights [79]. In this study, for interpolating SMC values at deep layer, the inputs $(\mathrm{x})$ were empirical SMC values for the surface layer and the deep layer during the training period. Then, all the resulting values were applied to determine the transfer function $S=\left[x_{\text {training }}, S M_{\text {training }}\right]^{T}$ and weights $\lambda^{(i)}$ to apply in formula [5]. 
Here, a Gaussian function was selected for the RBF network. Thus, the response of the hidden neuron to an input neuron $S$ is given by:

$$
\phi(S)=\exp \left(-\frac{\left\|S-c^{(i)}\right\|}{2 \sigma^{2}}\right)
$$

where $\phi()$ is the Gaussian activation function, and \|\| denotes the Euclidean distance, $c^{(i)}$ is the center of the $i$ th neuron in the hidden layer, and $\sigma$ is the width of the hidden neuron. It can be computed by [84]:

$$
\sigma=\frac{d_{\max }}{\sqrt{2 T}}
$$

where $d_{\max }$ is the maximum distance between centers of the hidden neurons and $T$ is the number of hidden neurons.

Finally, the RBF model is established as in the following formula:

$$
S M_{t_{n}}=\sum_{i=1}^{n} \lambda^{(i)} \phi^{(i)}(S)
$$

where $x_{\text {training }}$ is the surface soil moisture and $S M_{\text {training }}$ is the measured soil moisture value for the deep layer during the training period. The unit used is $\mathrm{cm}^{3} / \mathrm{cm}^{3}$. Then, the predicted surface soil moisture at selected times is input into the trained RBF model to obtain predicted soil moisture values for the deep layer. When RBF is applied in MATLAB, the spread (variance) influences its performance, and the results obtained, with spreads ranging from 0.0001 to 0.5 , are shown in Section 4.1.3.

\subsection{Linear Regression (LR)}

Linear regression was used to construct site-specific linear relationships between SMC in the near-surface $(4 \mathrm{~cm})$ layer and at deeper depths using the following formula [5]:

$$
S M_{t_{n}}=b+a x_{n}
$$

where $S M_{t_{n}}$ and $x_{n}$ are as above, $a$ is the regression coefficient, and $b$ is a constant.

\subsection{Calibrating Methods}

We used the MAE and RMSE to evaluate the moisture content in deep soil layers, derived using the four methods $[85,86]$, with the following formulas:

$$
\begin{gathered}
R M S E=\sqrt{\frac{1}{n} \sum_{i=1}^{n}\left(S M_{t_{n}}-S M_{t_{n}}^{*}\right)^{2}} \\
M A E=\frac{1}{n} \sum_{i=1}^{n}\left|S M_{t_{n}}-S M_{t_{n}}^{*}\right|
\end{gathered}
$$

where $S M_{t_{n}}\left(\mathrm{~cm}^{3} / \mathrm{cm}^{3}\right)$ is the observed soil moisture, $S M_{t_{n}}^{*}\left(\mathrm{~cm}^{3} / \mathrm{cm}^{3}\right)$ is the value predicted by one of the four extrapolation methods, and $n$ is the number of data points during a focal period.

Both MAE and RMSE are used to quantify errors between predicted and observed values. By definition, both measures are greater than zero, or equal zero if predicted values are identical to observed values [85-87]. Comparing them, the MAE value is better at reflecting the error between the predicted value and measured value, while the RMSE value is better at representing the relationship between the data series and the true value. 


\section{Results}

\subsection{Calibration of Three Methods in the Alpine Region}

For all the tested methods, with the exception of LR, there were important parameters that strongly affected their performance, such as the $T$ parameter in ExpF, which is insensitive to the location and season [5]. The kernels in SVR and spread in RBF also impacted the performance of the respective methods.

Thus, a key step was to identify the best parameters for the ExpF, SVR, and RBF methods in order to calibrate the functions for use in the alpine study area. For this, cross-validation was applied with 20 repetitions, in each case using a third of the dataset (randomly extracted) for training, and a third as the calibration set. The performance of the ExpF, SVR, and RBF methods with different parameters was then evaluated, as described in the following sections.

\subsubsection{Calibration of ExpF}

Previous studies have shown that the decay time $(T)$ is impacted by the soil depth or thickness [5,24]. The optimal value increases with increasing depth of soil, but also significantly varies among areas. Thus, we sought the optimal parameter $T$ for the 10 and $20 \mathrm{~cm}$ depths in the study area. Results obtained with $T$, ranging from 0.01 to 30 and showing values that generated the minimum RMSE and MAE for SMC in each depth, are presented in Figure 2. As found in previous studies, the effects of changes in $T$ on the methods' performance depended on the layer, and performance was poorer for the $20 \mathrm{~cm}$ layer than the $10 \mathrm{~cm}$ layer when $T$ exceeded 3 . The performance for both layers initially improved and then deteriorated with increases in $T$, and, for data collected from all stations, the optimal decay times were 6 and 0.5 for the 10 and $20 \mathrm{~cm}$ layers, respectively.

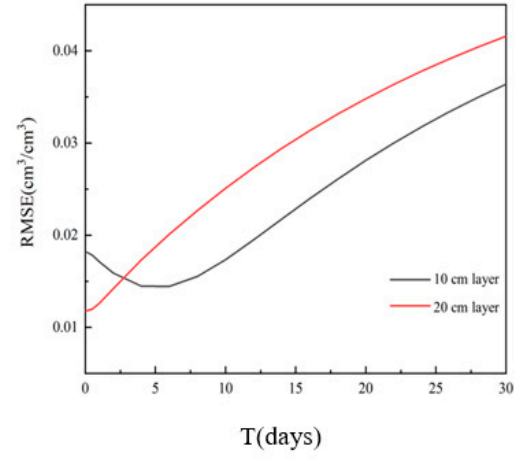

a

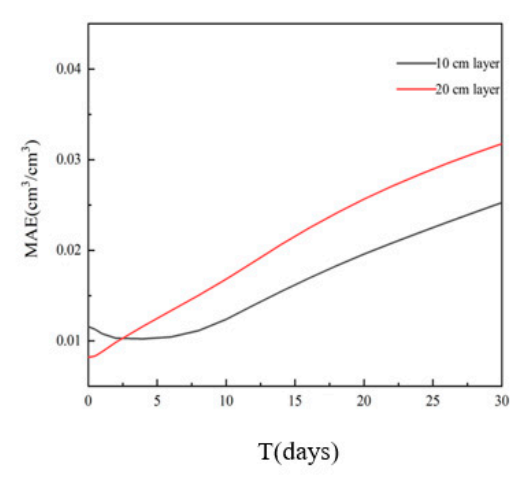

$\mathrm{b}$

Figure 2. Performance of the ExpF method with different decay times (T). (a). the RMSE of ExpF in the 10 and $20 \mathrm{~cm}$ layers (b1) and (b2); (b). the MAE of ExpF in these layers.

\subsubsection{Calibration of the SVR Function}

The SVR method's performance strongly depends on the kernel, which is incorporated to simplify computation of the inner product value of the transformed data in the feature space [73]. Determining the kernel and error penalty parameters for SVR is very problemdependent in practice. As previously mentioned, four types of kernels can be used. Thus, we also compared the performance of the method with each of these four types, for the 10 and $20 \mathrm{~cm}$ layers, and the results are shown in Figure 3. Minimization of RMSE and MAE at each depth showed that the optimal kernel function for both layers was the RBF, which is in accordance with many previous studies $[71,73,88]$. Thus, the RBF was selected as the kernel for the SVR method in the subsequent analysis. 


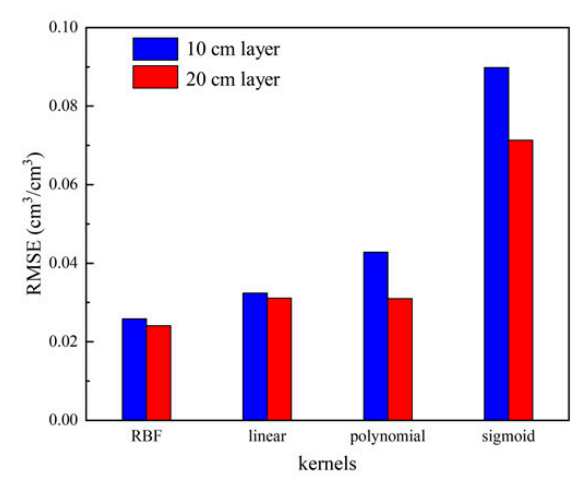

a

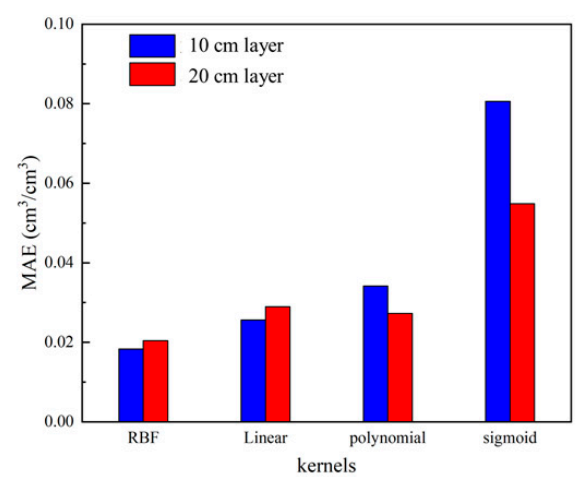

$\mathrm{b}$

Figure 3. Performance of the SVR method with indicated kernels. (a). the RMSE of SVR in the 10 and $20 \mathrm{~cm}$ layers; (b). the MAE of SVR in these layers.

\subsubsection{RBF Calibration}

The spread was one of the key factors affecting the RBF method's performance. Use of spread constants that are too large and too small resulted in underfitting and overfitting, respectively, due to the excessive and insufficient influence of general trends relative to finer-scale variations [89]. Thus, we compared the RBF method's performance with different spreads and sought the optimal spread parameters for the study area. Figure 4 shows the RMSE and MAE values obtained with spreads ranging from 0.0001 to 0.5 for the two soil layers. The method's performance for both layers first improved, then deteriorated as the spread increased, and the minimum RMSE and MAE were obtained with 0.01 and 0.05 spread values for the 10 and $20 \mathrm{~cm}$ layers, respectively. Thus, these values were selected as the optima.

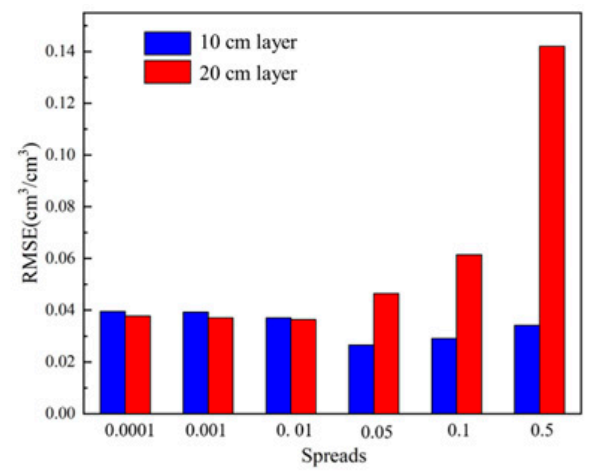

a

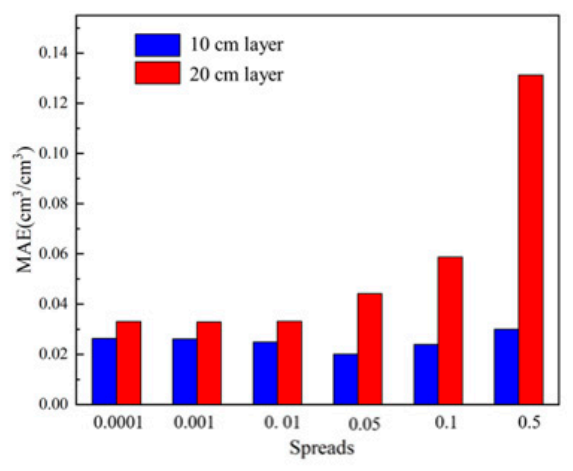

b

Figure 4. Performance of the RBF method with different spreads, (a). the RMSE of RBF in the 10 and $20 \mathrm{~cm}$ layers; (b). the MAE of RBF in these layers.

\subsection{Comparison of the Methods for the Entire Period}

The performance of the four vertical extrapolation methods for predicting SMC in the 10 and $20 \mathrm{~cm}$ layers during the same period (21 February 2014 to 21 August 2014), using the same training period (1 August 2013 to 20 February 2014), and in constant time for valid comparison, is shown in Figure 5. 

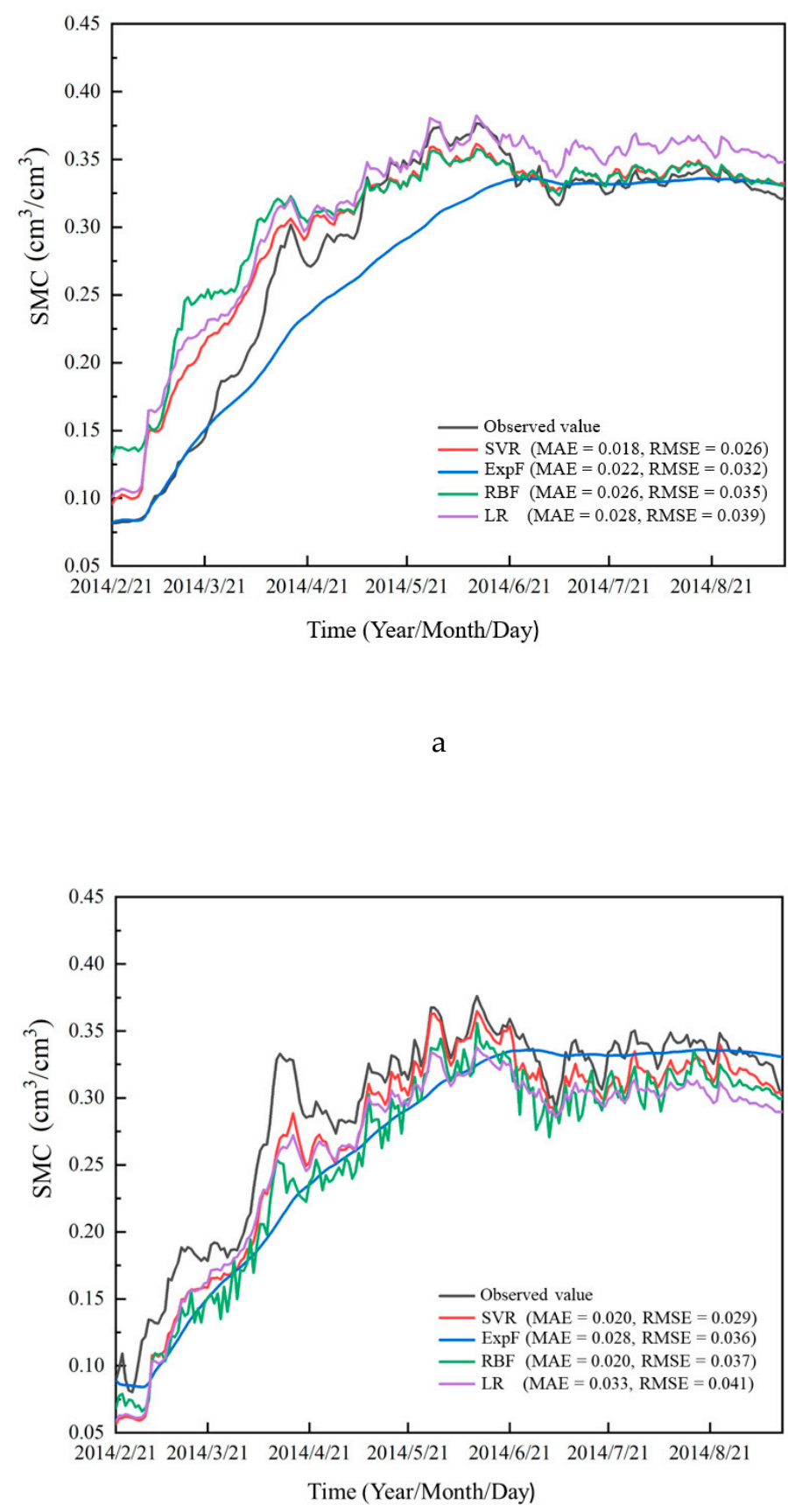

b

Figure 5. Observed soil moisture content (SMC) and values generated by the four extrapolation methods in the $10 \mathrm{~cm}$ layer (a) and $20 \mathrm{~cm}$ layer (b) during the period 21 February 2014-21 August 2014.

Both the MAE and RMSE values indicated that the SVR method consistently provided better SMC estimates for both soil layers, and all methods provided better estimates for the $10 \mathrm{~cm}$ layer than the $20 \mathrm{~cm}$ layer. In addition, the ExpF indicated the smoothest changes over time, while the other three indicated similar, more substantial fluctuations.

\subsection{Comparison of Different Methods Effected by Frozen Thaw}

\subsubsection{Sub-Division of the Study Period to Assess Freeze-Thaw Effects}

Numerous factors affect soil moisture contents at different scales in every area $[88,90]$. For the focal environment and scale here, the most important variables were deemed to be 
soil temperature, the normalized difference vegetation index (NDVI), and precipitation, all of which significantly affect SMC according to previous studies [52,91-95].

Figure 6a shows observed changes in daily moisture contents in the three soil layers and precipitation in and around the study area. As shown in Figure 6a, most precipitation (479 mm in total) occurred from 1 August 2013 to 11 September 2013, and 10 May 2014 to 12 September 2014. In the period from 12 September 2013 to 3 May 2014 only $57.68 \mathrm{~mm}$ fell, and even less fell between 20 November 2013 and 12 March 2014, resulting in rapid reduction in SMC and stabilization at a very low level. As the frequency and abundance of precipitation increased, the SMC quickly increased and stabilized at around $0.3-0.4 \mathrm{~cm}^{3} / \mathrm{cm}^{3}$, clearly showing (as expected) that the precipitation affected the SMC.

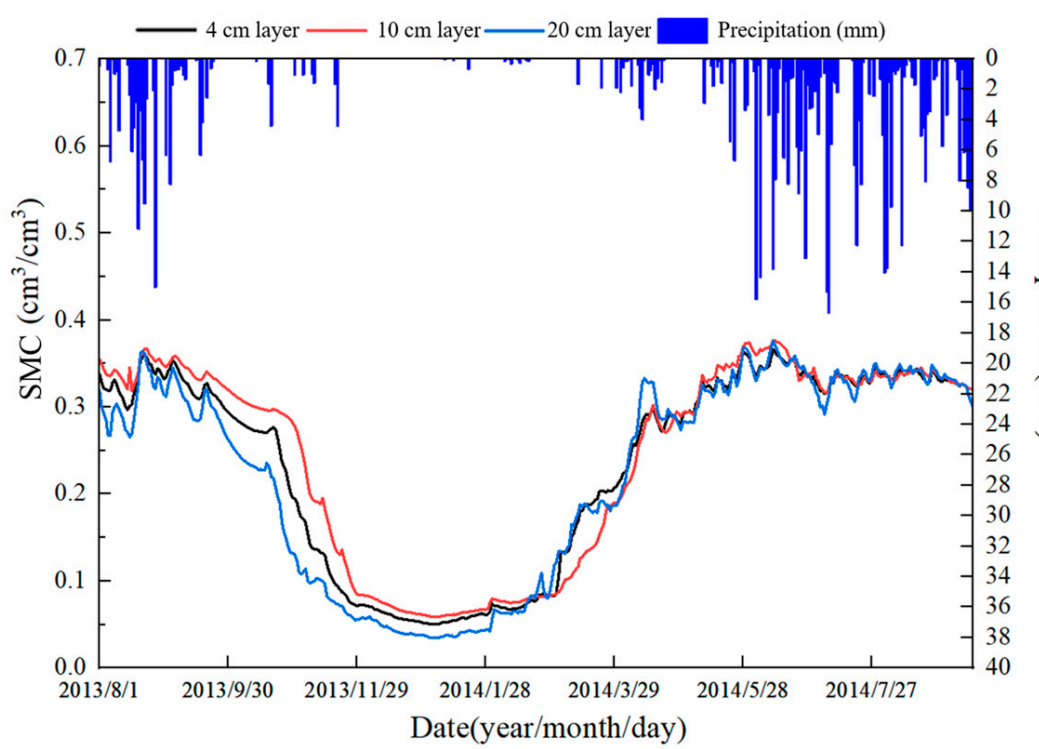

(a)

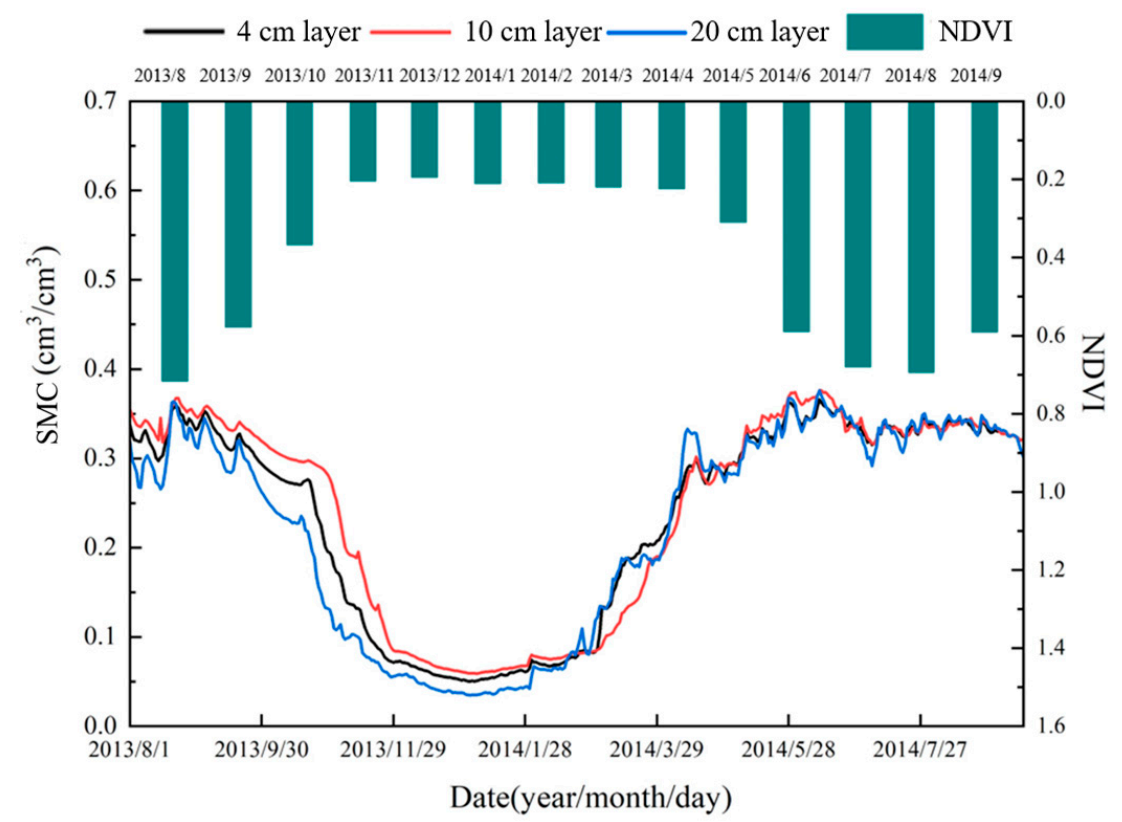

(b)

Figure 6. Cont. 

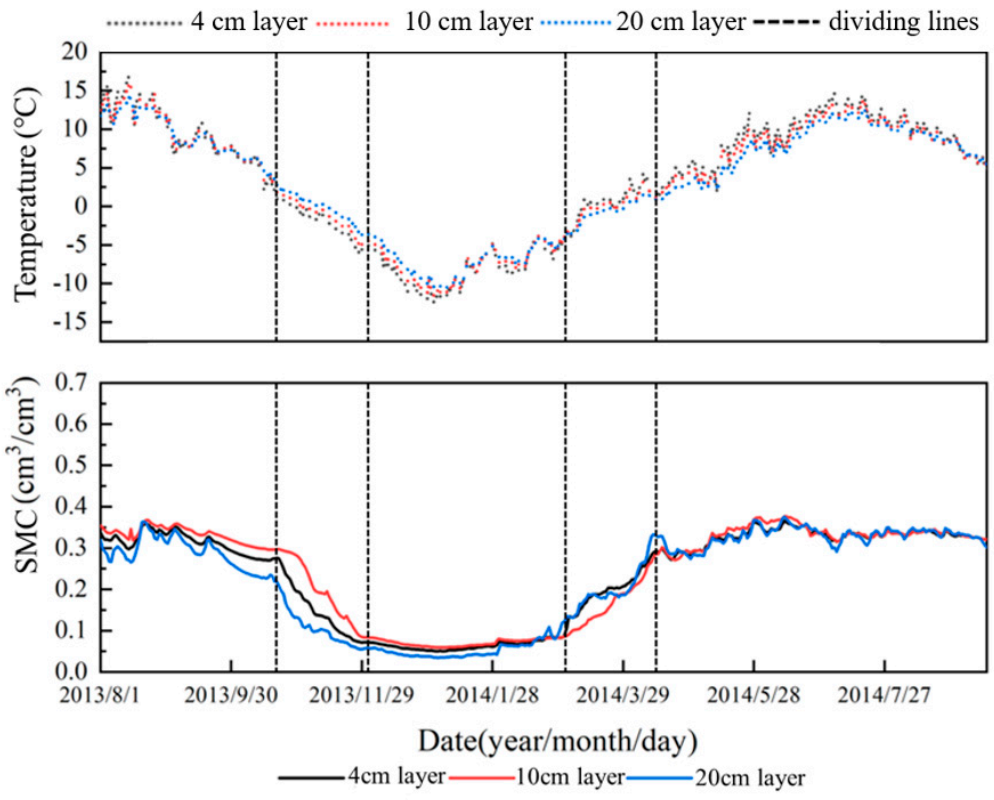

(c)

Figure 6. Performance of the four methods for estimating SMC in the $4 \mathrm{~cm}, 10 \mathrm{~cm}$, and $20 \mathrm{~cm}$ layers with variation in precipitation (a), NDVI (b), and soil temperature (c).

Figure $6 \mathrm{~b}$ shows the daily SMC of the three layers and NDVI in each month during the study period. The SMC generally increased with increases in NDVI. However, in November, the NDVI was 0.203 , close to the lowest recorded value in the study, but the SMC was still relatively high. Similarly, in both April and May, the NDVI values were still low, but the soil SMC values were among the highest in the study period.

Comparison of the measurements of SMC and soil temperature in the three layers clearly showed that the soil temperature also affected SMC (Figure 6c). The performance of the correlation coefficient of the three layers with precipitation, soil temperature, and NDVI showed that the correlation coefficients between SMC and soil temperature were much larger than others (Table 1), representing the fact that the soil temperature had significant impacts on SMC. When the temperature was below a threshold value (around $0{ }^{\circ} \mathrm{C}$ ), SMC quickly declined to a low level, while, when above the threshold, it rapidly increased to a higher level. This can be largely attributed to freeze-thawing of the soil, which affects SMC by changing the soil water phase (Wang et al., 2020). As soils freeze and their liquid water content declines, a strong gradient in matric potential develops, which drives the water toward the freezing front $[5,93]$. When the soil is completely frozen, a small amount of water is still present in a "supercooled" state [96], and when the soil rapidly thaws in spring, the SMC quickly increases.

Table 1. The performance of correlation coefficient of the three layers with precipitation, soil temperature, and NDVI.

\begin{tabular}{cccc}
\hline & $\mathbf{4} \mathbf{c m}$ Layer & $\mathbf{1 0 ~} \mathbf{c m}$ Layer & $\mathbf{2 0 ~ c m ~ L a y e r ~}$ \\
\hline Precipitation & $0.368^{*}$ & $0.344^{*}$ & $0.368^{*}$ \\
Soil Temperature & $0.928^{*}$ & $0.937^{*}$ & $0.907^{*}$ \\
NDVI & $0.794^{*}$ & $0.809 *$ & $0.794^{*}$ \\
\hline
\end{tabular}

NOTE: * Correlations significant at the $p<0.05$ level.

In combination, these observations clearly showed that SMC varied seasonally in the focal area during the study period, and four clear sub-periods were distinguished. SMC was relatively high and stable from 1 August 2013 to 27 October 2013, rapidly declined from 28 October 2013 to 28 November 2013, remained low, but stable from 29 October 2013 
to 10 March 2014, and quickly increased from 11 March 2014 to 11 April 2014 (hereafter periods 1, 2, 3, and 4, respectively).

4.3.2. Comparison of the Four Methods' Performance for Estimating SMC in the Four Sub-Periods

As described in Section 4.3.1, the methods' performance significantly varied with time, which was apparently due to shifts in SMC between liquid and ice states. Thus, freeze-thaw effects on the performance of each extrapolation method were assessed in more detail. MAE and RMSE values obtained for SMC in the 10 and $20 \mathrm{~cm}$ layers during the four mentioned sub-periods clearly confirmed that all four methods' performance varied among these sub-periods (Figure 7).

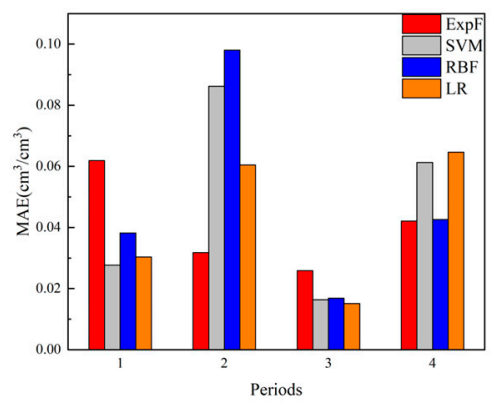

al

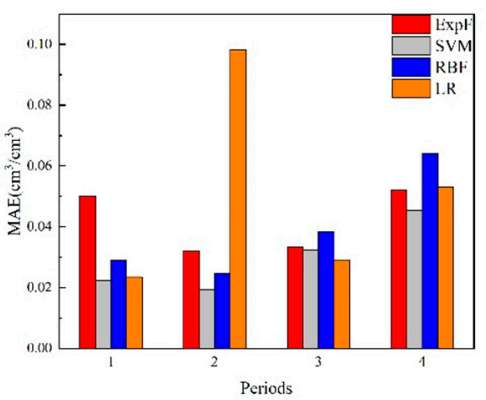

b1

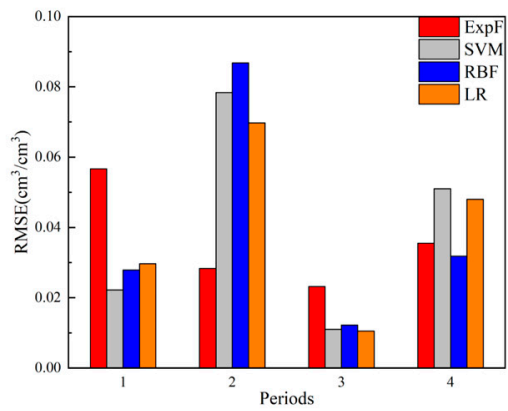

a2

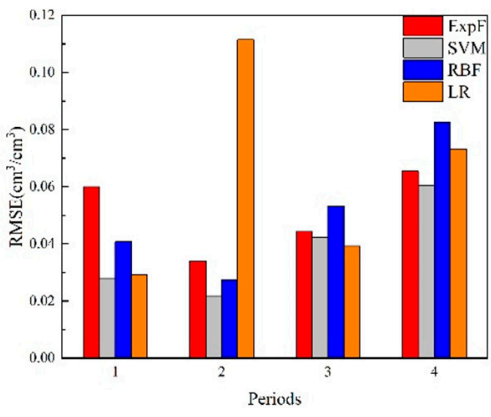

b2

Figure 7. Performance of the four methods for assessing SMC during four periods defined in the text, in terms of MAE of SMC in the 10 and $20 \mathrm{~cm}$ layers (a1) and (a2), respectively, and RMSE of SMC in these layers (b1) and (b2), respectively.

For estimating SMC in the $10 \mathrm{~cm}$ layer, the ExpF method's performance was best for period 3, followed by periods 2, 4, and 1, while the other three methods' performance was best for period 3 followed by periods 1, 4, and 2. In addition, the ExpF method provided substantially better estimates than the other methods for period 2, but substantially worse estimates for period 1. For estimating SMC in the $20 \mathrm{~cm}$ layer, the ExpF method's performance was best for period 3 , followed by periods 2,4 , and 1 , while the other three methods' performance was best for period 3 followed by periods 1, 4, and 2 . The LR method provided particularly poor estimates for SMC in this layer during period 2.

\subsection{Comparison of the Methods for Estimating SMC in Different Layers}

As previously mentioned, there were clear between-depth differences in the performance of each extrapolation method, in constant time, during the four periods. Thus, coefficients of correlation between surface $(4 \mathrm{~cm})$ layer measurements of SMC and the 10 and $20 \mathrm{~cm}$ layers were calculated, and, as shown in Table 2, in all cases they were significant at the $p<0.05$ level. However, correlation coefficients were significantly larger for the $10 \mathrm{~cm}$ layer than the $20 \mathrm{~cm}$ layer in periods 1 and 3 . In addition, coefficient of variation 
$(\mathrm{CV})$ values for the $20 \mathrm{~cm}$ layer increased in the four periods in the order of $2<3<1<4$, while the corresponding order for the $10 \mathrm{~cm}$ layer was $3<1<4<2$. CV values were also larger for the $20 \mathrm{~cm}$ layer than the $10 \mathrm{~cm}$ layer in each period, except period 2.

Table 2. The performance of correlation coefficient and CV at two layers at four periods together.

\begin{tabular}{ccccccc}
\hline & & $\mathbf{1}$ & $\mathbf{2}$ & $\mathbf{3}$ & $\mathbf{4}$ & Total \\
\hline \multirow{2}{*}{$10 \mathrm{~cm}$ layer } & $\mathrm{r}$ & $0.874^{*}$ & $0.815^{*}$ & $0.917 *$ & $0.681^{*}$ & $0.982 *$ \\
& $\mathrm{CV}$ & 0.220 & 0.375 & 0.147 & 0.262 & 0.471 \\
\hline \multirow{2}{*}{$20 \mathrm{~cm}$ layer } & $\mathrm{r}$ & $0.850 *$ & $0.897 *$ & $0.902 *$ & $0.892 *$ & $0.987^{*}$ \\
& $\mathrm{CV}$ & 0.270 & 0.220 & 0.410 & 0.630 & 0.527 \\
\hline
\end{tabular}

NOTE: * Correlations significant at the $p<0.05$ level.

\section{Discussion}

\subsection{Effects of Environmental Factors on Method Performance}

As described in Section 4.2, four periods with clearly differing SMC regimes were discerned during the total study period, when SMC was relatively high and stable, rapidly decreasing, low and stable, and rapidly increasing (designated periods 1-4, respectively). Changes in temperature were the main reasons for variations in periods 2,3 , and 4 .

In a previous study, the temperature clearly affected vertical extrapolation methods' performance and, thus, was used to divide the annual SMC cycle into two periods in Oklahoma, USA: warm and cold [5]. The cited authors found that the vertical extrapolation methods they tested provided better estimates of SMC in the warm season than in the cool season, at least for the $60-75 \mathrm{~cm}$ layer. The focal area in this study is much more mountainous and has much colder temperatures than Oklahoma, thus there is much higher variance in soil moisture and freeze-thawing is a much more important process [97]. There are clearly four differing seasonal periods, and differences among them substantially affect the methods' performance, even for estimating SMC in a shallow layer (ca. $10 \mathrm{~cm}$ ) as aforementioned. When freezing begins, SMC rapidly decreases and remains stable, if most of the soil moisture is converted from liquid water to ice, until thawing begins in spring, when the SMC quickly increases then remains stable if almost all soil moisture changes from ice to liquid water. Furthermore, freeze-thawing also affects infiltration [98], thus causing major fluctuations in SMC and the extrapolation methods' performance.

\subsection{Mechanistic Reasons for Differences in the Methods' Performance}

A comparison of the results obtained with the four extrapolation methods showed that the SVR method provided the best estimates of SMC in both 10 and $20 \mathrm{~cm}$ layers during the total study period, followed by the ExpF, RBF, and LR methods. There are three clear mechanistic reasons for the differences in their performance. First, the relationship between surface and deep SMC is non-linear [6-8]. Thus, the LR method (the only linear approach tested) could not provide as accurate estimates of deep SMC from surface soil measurements as non-linear methods, as shown by this study and that of Zhang et al. (2017) [5]. Second, unlike the other two non-linear methods, the ExpF function extrapolated deep soil SMC directly from surface soil moisture measurements without using any training data [30]. Thus, its performance would be much better when the vertical infiltration rate of soil moisture is relatively fast, or the interaction between surface and soil moisture and deep soil moisture is rapid, than in other cases. A previous study found that it performs better than ANN methods because it can better capture the relative variability and correlation between SMC at different depths [5]. We also found that it performed better than the RBF method. However, infiltration patterns in focal alpine area are very complex, and because an assumption underlying the ExpF method is that absolute water contents among the layers are similar, it performs less well than the SVR method in constant time. Third, the SVR and RBF methods are very similar, with both predicting values by fitting training functions through minimizing differences between observation and training values. 
However, SVR is superior to the RBF method, partly because SVR is based on structural risk minimization, minimizing an upper bound for the generalization error, while the RBF method is based on empirical risk minimization, i.e., minimizing the training error. Moreover, SVR provides a global optimal solution and the parameter selection is less complex, so the RBF method is prone to higher uncertainty during the fitting process and can less easily generate optimal solutions in many cases [44,99], especially over longer forecasting horizons [100]. As its optimization goal is to minimize the structural risk rather than the empirical risk, and it has excellent generalization ability, SVR has become one of the most commonly used and effective methods. It can provide much better results than other algorithms with small sample training sets, thus it reduces dataset size and data distribution requirements by maximizing margins between classes and thereby acquiring a structural description of log data distributions. In summary, due to the complexity of the vertical infiltration processes, non-linear methods are intrinsically more suitable than linear methods; SVR performs better than the other two tested non-linear methods (RBF and ExpF); and SVR is both much faster and performs significantly better than RBF methodology.

\subsection{Effects of the Freeze-Thaw Process on Method Performance}

As already mentioned, the performance of the four extrapolation methods for estimating SMC significantly differed among the four identified periods. For the $10 \mathrm{~cm}$ layer, the ExpF method provided the best estimates in period 3, followed by periods 2, 4, and 1 , while the performance of the other three methods was maximal in period 3 followed by periods 1,2 , and 4 . For the $20 \mathrm{~cm}$ layer, the LR method provided the best estimates in period 1 , followed by periods 3,4 , and 2 , while the corresponding sequence for the other methods was periods $2,1,3$, and 4 . There are three main reasons for these variations. First, differences in SMC variability among the periods affected the methods' performance. The CV values were lowest in period 3, followed by periods 1,4 , and 2 for the $10 \mathrm{~cm}$ layer, while the corresponding order for the $20 \mathrm{~cm}$ layer was 2, 1, 3, and 4 (Table 2). This is important because, as previous authors have noted, increases in the variability in soil moisture will inevitably impair the performance of calibration methods [101,102]. Second, there are clear mechanistic reasons for the differences in the methods' performance. In contrast to the other methods, the ExpF method predicted SMC values for a given moment (day) from values in the previous moment. Both the measured SMC in the surface layer and predicted SMC in deep layers in the preceding moment determined the deep SMC at a given moment. Thus, the variations in $\mathrm{CV}$ values among periods did not significantly affect the ExpF method's performance. Third, there were substantial anomalies between the trends in the SMC values generated by the LR method and the CV values, largely due to the complex, non-linear, vertical movement of soil moisture. The lag times between responses of other layers to changes in the surface layer were depth-dependent, so correlation coefficients between SMC in the $10 \mathrm{~cm}$ layer at a given moment and surface soil moisture in the preceding moment during periods 1 to 4 were $0.772,0.835,0.930$, and 0.684 , respectively, all of which were significant at the $p<0.05$ level. With increasing depth, this correlation weakened and eventually disappeared. Both the SVR and RBF are self-learning methods, and thus find the relationship between SMC in the surface soil and deeper layers at different moments from training data. As a result, their performance is not significantly correlated with the CV values.

\subsection{Performance of the Extrapolation Methods at Different Depths}

In accordance with findings by Zhang et al. (2017) [5], the four methods provided consistently better estimates of SMC in the $10 \mathrm{~cm}$ layer than in the $20 \mathrm{~cm}$ layer, both in terms of constant time and specific periods. SMC also had a smaller CV in the $10 \mathrm{~cm}$ layer than in the $20 \mathrm{~cm}$ layer, both for the entire period ( 0.471 and 0.527 , respectively) and the four sub-periods. The CV was the most commonly used index to describe the variability of geographical elements because it is dimensionless. As it increases, the variability of soil 
moisture rises, and the performance of calibration methods tends to decline [101,102], thus explaining the better performance of the four extrapolation methods for SMC in the $10 \mathrm{~cm}$ layer than in the $20 \mathrm{~cm}$ layer.

\section{Conclusions}

In the present study, we used daily records of soil moisture, soil temperature, and precipitation in an alpine area, located in the Qilian Mountain, to assess four extrapolation methods (SVR, ExpF, RBF, and LR) used for predicting SMC in 10 and $20 \mathrm{~cm}$ soil layers from surface soil measurements, with consideration of the variance of soil moisture and the effects of freeze-thaw processes. There are three main conclusions:

1. The freeze-thaw process significantly impacted the SMC and performance of extrapolation methods, as it greatly increased the complexity and temporal heterogeneity of infiltration processes. Environmental factors (e.g., soil temperature, precipitation, and NDVI) were also clearly correlated with soil moisture. The freeze-thaw process caused major fluctuations in the SMC via correlation analysis and through the extrapolation methods' performance. Thus, the influence of the freeze-thaw process should be considered when applying extrapolating methods in an alpine area;

2. The SVR can be adapted to the variance in data through training its function by selflearning with small datasets. Thus, the SVR is most suitable for extrapolating SMC values, particularly in areas with complex environmental factors and movements of soil moisture;

3. The performance of extrapolation methods was correlated with the variability in soil moisture in focal layers, thus the performance of all extrapolation methods was better for the $10 \mathrm{~cm}$ layer than the $20 \mathrm{~cm}$ layer.

In conclusion, the SVR was determined to be the best current choice for extrapolating $\mathrm{SMC}$ in alpine areas in which freeze-thawing increases the complexity of infiltration processes and, thus, is an important factor. When the datasets are small, the advantage of SVR is obvious. Furthermore, soil temperature was a very important factor, which affected the extrapolation methods' performance.

Author Contributions: Methodology, software and validation J.L.; writing-original draft preparation, J.L.; writing - review and editing, L.Z. All authors have read and agreed to the published version of the manuscript.

Funding: The project was partially funded by the Natural Science projects of the Department of Science, Northwest Normal University (grant no. NWNU-vvvvvvvvvvvLKQN2020-19), the National Natural Science Foundation of China (grant no. 41877148) and the Department of Education of Gansu Province (grant no. 2021B-077).

Institutional Review Board Statement: Not applicable.

Informed Consent Statement: Not applicable.

Data Availability Statement: Not applicable.

Acknowledgments: We are grateful to the staff associated with the HiWATER program for their hard work in collecting soil moisture data. The authors are also grateful to anonymous referees for constructive comments that helped to improve the quality of the article.

Conflicts of Interest: The authors declare no conflict of interest.

\section{References}

1. Vereecken, H.; Huisman, J.A.; Pachepsky, Y.; Montzka, C.; van der Kruk, J.; Bogena, H.; Weihermüller, L.; Herbst, M.; Martinez, G.; Vanderborght, J. On the spatio-temporal dynamics of soil moisture at the field scale. J. Hydrol. 2014, 516, 76-96. [CrossRef]

2. Gao, J.; Yan, Y.; Hou, X.; Liu, X.; Zhang, Y.; Huang, S.; Wang, P. Vertical distribution and seasonal variation of soil moisture after drip-irrigation affects greenhouse gas emissions and maize production during the growth season. Sci. Total Environ. 2021, 763, 142965. [CrossRef] [PubMed]

3. Zhou, S.; Williams, A.P.; Lintner, B.; Berg, A.M.; Gentine, P. Soil moisture-atmosphere feedbacks mitigate declining water availability in drylands. Nat. Clim. Chang. 2021, 11. [CrossRef] 
4. Tóth, B.; Szatmári, G.; Takács, K.; Laborczi, A.; Makó, A.; Rajkai, K.; Pásztor, L. Mapping soil hydraulic properties using random forest based pedotransfer functions and geostatistics. Hydrol. Earth Syst. Sci. 2019, 23, 2615-2635.

5. Zhang, N.; Quiring, S.; Ochsner, T.; Ford, T. Comparison of three methods for vertical extrapolation of soil moisture in Oklahoma. Vadose Zone J. 2017, 16, 1-19. [CrossRef]

6. Wang, Y.; Shao, M.; Zhu, Y.; Liu, Z. Impacts of land use and plant characteristics on dried soil layers in different climatic regions on the Loess Plateau of China. Agric. For. Meteorol. 2011, 151, 437-448. [CrossRef]

7. Han, E.; Heathman, G.C.; Merwade, V.; Cosh, M. Application of observation operators for field scale soil moisture averages and variances in agricultural landscapes. J. Hydrol. 2012, 444-445, 34-50. [CrossRef]

8. Gao, X.; Li, H.; Zhao, X.; Ma, W.; Wu, P. Identifying a suitable revegetation technique for soil restoration on water-limited and degraded land: Considering both deep soil moisture deficit and soil organic carbon sequestration. Geoderma 2018, 319, 61-69. [CrossRef]

9. Gao, X.; Zhao, X.; Brocca, L.; Pan, D.; Wu, P. Testing of observation operators designed to estimate profile soil moisture from surface measurements. Hydrol. Process. 2018, 33, 575-584. [CrossRef]

10. Millard, K.; Richardson, M. Quantifying the relative contributions of vegetation and soil moisture conditions to polarimetric C-Band SAR response in a temperate peatland. Remote Sens. Environ. 2018, 206, 123-138. [CrossRef]

11. Chen, R.S.; Lü, S.H.; Ersi, K.; Ji, X.B.; Yang, Y.; Zhang, J.S. A distributed water-heat coupled (DWHC) model for mountainous watershed of an inland river basin (I): Model structure and equations (in Chinese). Adv. Earth Sci. 2006, 21, 806-818.

12. Katuwal, S.; Knadel, M.; Moldrup, P.; Norgaard, T.; Greve, M.H.; de Jonge, L.W. Visible-near-infrared spectroscopy can predict mass transport of dissolved chemicals through intact soil. Sci. Rep. 2008, 8, 1-9. [CrossRef]

13. Zarlenga, A.; Fiori, A.; Russo, D. Spatial variability of soil moisture and the scale issue: A geostatistical approach. Water Resour. Res. 2008, 54, 1765-1780. [CrossRef]

14. Ferrara, C.; Barone, P.M.; Steelman, C.M.; Pettinelli, E.; Endres, A. Monitoring shallow soil water content under natural field conditions using the early-time GPR signal technique. Vadose Zone J. 2013, 12, vzj2012. [CrossRef]

15. Baatz, R.; Bogena, H.; Franssen, H.-J.H.; Huisman, J.A.; Qu, W.; Montzka, C.; Vereecken, H. Calibration of a catchment scale cosmic-ray probe network: A comparison of three parameterization methods. J. Hydrol. 2014, 516, 231-244. [CrossRef]

16. Brocca, L.; Hasenauer, S.; Lacava, T.; Melone, F.; Moramarco, T.; Wagner, W.; Dorigo, W.; Matgen, P.; Martínez-Fernández, J.; Llorens, P.; et al. Soil moisture estimation through ASCAT and AMSR-E sensors: An intercomparison and validation study across Europe. Remote Sens. Environ. 2011, 115, 3390-3408. [CrossRef]

17. Panciera, R.; Walker, J.P.; Jackson, T.J.; Gray, D.A.; Tanase, M.A.; Ryu, D.; Monerris, A.; Yardley, H.; Rüdiger, C.; Wu, X.; et al. The soil moisture active passive experiments (SMAPEx): Toward soil moisture retrieval from the SMAP mission. IEEE Trans. Geosci. Remote Sens. 2013, 52, 490-507. [CrossRef]

18. Quiring, S.M.; Ford, T.W.; Wang, J.K.; Khong, A.; Harris, E.; Lindgren, T.; Goldberg, D.W.; Li, Z. The North American soil moisture database: Development and applications. Bull. Am. Meteorol. Soc. 2016, 97, 1441-1459. [CrossRef]

19. Su, S.L.; Singh, D.; Baghini, M.S. A critical review of soil moisture measurement. Measurement 2014, 54, 92-105. [CrossRef]

20. Wang, Q.F.; Zhang, T.J.; Jin, H.J.; Cao, B.; Peng, X.Q. Observational study on the active layer freeze-thaw cycle in the upper reaches of the Heihe River of the north-eastern Qinghai-Tibet plateau. Quat. Int. 2018, 475, 63-69. [CrossRef]

21. Cho, E.; Choi, M.; Wagner, W. An assessment of remotely sensed surface and root zone soil moisture through active and passive sensors in northeast Asia. Remote Sens. Environ. 2015, 160, 166-179. [CrossRef]

22. Dumedah, G.; Walker, J.; Merlin, O. Root-zone soil moisture estimation from assimilation of downscaled Soil Moisture and Ocean Salinity data. Adv. Water Resour. 2015, 84, 14-22. [CrossRef]

23. Das, N.N.; Mohanty, B.P. Root zone soil moisture assessment using remote sensing and vadose zone modeling. Vadose Zone J. 2006, 5, 296-307. [CrossRef]

24. Albergel, C.; Rüdiger, C.; Pellarin, T.; Calvet, J.-C.; Fritz, N.; Froissard, F.; Suquia, D.; Petitpa, A.; Piguet, B.; Martin, E. From near-surface to root-zone soil moisture using an exponential filter: An assessment of the method based on in-situ observations and model simulations. Hydrol. Earth Syst. Sci. 2008, 12, 1323-1337. [CrossRef]

25. Hu, W.; Si, B. Can soil water measurements at a certain depth be used to estimate mean soil water content of a soil profile at a point or at a hillslope scale? J. Hydrol. 2014, 516, 67-75. [CrossRef]

26. Manfreda, S.; Brocca, L.; Moramarco, T.; Melone, F.; Sheffield, J. A physically based approach for the estimation of root-zone soil moisture from surface measurements. Hydrol. Earth Syst. Sci. 2014, 18, 1199-1212. [CrossRef]

27. Yu, L.; Zeng, Y.; Su, Z.; Cai, H.; Zheng, Z. The effect of different evapotranspiration methods on portraying soil water dynamics and ET partitioning in a semi-arid environment in Northwest China. Hydrol. Earth Syst. Sci. 2016, 20, 975-990. [CrossRef]

28. Bezerra, B.G.; Dos Santos, C.A.C.; Da Silva, B.B.; Pérez-Marin, A.M.; Bezerra, M.V.C.; Bezerra, J.R.C.; Rao, T.V.R. Estimation of soil moisture in the root-zone from remote sensing data. Rev. Bras. Cienc. Solo 2013, 37, 596-603. [CrossRef]

29. Santos, W.J.R.; Silva, B.M.; Oliveira, G.C.; Volpato, M.M.L.; Lima, J.; Curi, N.; Marques, J.J. Soil moisture in the root zone and its relation to plant vigor assessed by remote sensing at management scale. Geoderma 2014, 221-222, 91-95. [CrossRef]

30. Wagner, W.; Lemoine, G.; Rott, H. A method for estimating soil moisture from ERS scatterometer and soil data. Remote Sens. Environ. 1999, 70, 191-207. [CrossRef]

31. Kornelsen, K.; Coulibaly, P. Root-zone soil moisture estimation using data-driven methods. Water Resour. Res. 2014, 50, 2946-2962. [CrossRef] 
32. Calvet, J.-C.; Fritz, N.; Froissard, F.; Suquia, D.; Petitpa, A.; Piguet, B. In situ soil moisture observations for the CAL/VAL of SMOS: The SMOSMANIA network. In Proceedings of the International Geoscience and Remote Sensing Symposium-IGARSS, Barcelona, Spain, 23-28 July 2007; pp. 1196-1199. [CrossRef]

33. Sabater, J.M.; Jarlan, L.; Calvet, J.-C.; Bouyssel, F.; De Rosnay, P. From near-surface to root-zone soil moisture using different assimilation techniques. J. Hydrometeorol. 2007, 8, 194-206. [CrossRef]

34. Jackson, T.J. Soil water modeling and remote sensing. IEEE Trans. Geosci. Remote Sens. 1986, 24, 37-46. [CrossRef]

35. Shi, Y.; Wu, P.; Zhao, X.; Li, H.; Wang, J.; Zhang, B. Statistical analyses and controls of root-zone soil moisture in a large gully of the Loess Plateau. Environ. Earth Sci. 2013, 71, 4801-4809. [CrossRef]

36. Heung, B.; Hodúl, M.; Schmidt, M.G. Comparing the use of training data derived from legacy soil pits and soil survey polygons for mapping soil classes. Geoderma 2017, 290, 51-68. [CrossRef]

37. Dornik, A.; Dragut, L.; Urdea, P. Classification of soil types using geographic object-based image analysis and random forests. Pedosphere 2018, 28, 913-925. [CrossRef]

38. Akumu, C.; Johnson, J.; Etheridge, D.; Uhlig, P.; Woods, M.; Pitt, D.; McMurray, S. GIS-fuzzy logic based approach in modeling soil texture: Using parts of the clay belt and Hornepayne region in Ontario Canada as a case study. Geoderma 2015, 239-240, 13-24. [CrossRef]

39. Meng, E.; Huang, S.; Huang, Q.; Fang, W.; Wu, L.; Wang, L. A robust method for non-stationary streamflow prediction based on improved EMD-SVM model. J. Hydrol. 2018, 568, 462-478. [CrossRef]

40. Wang, W.C.; Chau, K.W.; Cheng, C.T.; Qiu, L. A comparison of performance of several artificial intelligence methods for forecasting monthly discharge time series. J. Hydrol. 2009, 374, 294-306. [CrossRef]

41. Maity, R.; Bhagwat, P.P.; Bhatnagar, A. Potential of support vector regression for prediction of monthly streamflow using endogenous property. Hydrol. Process. 2010, 24, 917-923. [CrossRef]

42. Lafdani, E.K.; Nia, A.M.; Ahmadi, A. Daily suspended sediment load prediction using artificial neural networks and support vector machines. J. Hydrol. 2013, 478, 50-62. [CrossRef]

43. Liu, M.; Lu, J. Support vector machine-An alternative to artificial neuron network for water quality forecasting in an agricultural nonpoint source polluted river? Environ. Sci. Pollut. Res. 2014, 21, 11036-11053. [CrossRef]

44. Chen, W.-H.; Hsu, S.-H.; Shen, H.-P. Application of SVM and ANN for intrusion detection. Comput. Oper. Res. 2005, 32, 2617-2634. [CrossRef]

45. Vivoni, E.R.; Rodríguez, J.C.; Watts, C.J. On the spatiotemporal variability of soil moisture and evapotranspiration in a mountainous basin within the north American monsoon region. Water Resour. Res. 2010, 46. [CrossRef]

46. Yang, X.H.; Yao, T.D.; He, Y.Q. The role of soil moisture-energy distribution and melting-freezing processes on seasonal shift in Tibetan Plateau (in Chinese). J. Mt. Sci. 2002, 20, 553-558. [CrossRef]

47. Derksen, C.; Xu, X.; Dunbar, R.S.; Colliander, A.; Kim, Y.; Kimball, J.S.; Black, T.A.; Euskirchen, E.; Langlois, A.; Loranty, M.; et al. Retrieving landscape freeze/thaw state from soil moisture active passive (SMAP) radar and radiometer measurements. Remote Sens. Environ. 2017, 194, 48-62. [CrossRef]

48. Yang, K.; Wang, C. Seasonal persistence of soil moisture anomalies related to freeze-thaw over the Tibetan Plateau and prediction signal of summer precipitation in eastern China. Clim. Dyn. 2019, 53, 2411-2424. [CrossRef]

49. Bao, H.; Koike, T.; Yang, K.; Wang, L.; Shrestha, M.; Lawford, P. Development of an enthalpy-based frozen soil model and its validation in a cold region in China. J. Geophys. Res. Atmos. 2016, 121, 5259-5280. [CrossRef]

50. Hu, G.; Zhao, L.; Wu, X.; Li, R.; Wu, T.; Xie, C.; Pang, Q.; Zou, D. Comparison of the thermal conductivity parameterizations for a freeze-thaw algorithm with a multi-layered soil in permafrost regions. Catena 2017, 156, 244-251. [CrossRef]

51. Yang, K.; Wang, C.; Li, S. Improved simulation of frozen-thawing process in land surface model (CLM4.5). J. Geophys. Res. Atmos. 2018, 123, 13-238. [CrossRef]

52. Wang, X.; Xie, H.; Guan, H.; Zhou, X. Different responses of MODIS-derived NDVI to root-zone soil moisture in semi-arid and humid regions. J. Hydrol. 2007, 340, 12-24. [CrossRef]

53. Wang, C.; Yang, K.; Zhang, F. Impacts of soil freeze-thaw process and snow melting over Tibetan Plateau on Asian summer monsoon system: A review and perspective. Front. Earth Sci. 2020, 8, 133. [CrossRef]

54. Zhang, R.; Zuo, Z. Impact of spring soil moisture on surface energy balance and summer monsoon circulation over East Asia and precipitation in East China. J. Clim. 2011, 24, 3309-3322. [CrossRef]

55. Meng, X.; Li, R.; Luan, L.; Lyu, S.; Zhang, T.; Ao, Y.; Han, B.; Zhao, L.; Ma, Y. Detecting hydrological consistency between soil moisture and precipitation and changes of soil moisture in summer over the Tibetan Plateau. Clim. Dyn. 2017, 51, 4157-4168. [CrossRef]

56. Yang, K.; Hu, T.; and Wang, C. A numerical study on the relationship between the spring-winter snow cover anomalies over the northern and southern Tibetan Plateau and summer precipitation in East China. Chin. J. Atmos. Sci. 2017, 41, 345-356. [CrossRef]

57. Wang, C.; Cui, Y. Characteristics of the difference of temperature between surface and atmosphere over the Tibetan Plateau in the early stage of East Asian summer monsoon onset. Clim. Environ. Res. 2011, 16, 586-596.

58. Yang, K.; Wang, C. 2019. Water storage effect of soil freeze-thaw process and its impacts on soil hydro-thermal regime variations. Agric. For. Meteorol. 2019, 265, 280-294. [CrossRef]

59. Li, X.; Liu, S.; Li, H.; Ma, M.; Wang, J.; Xiao, Q.; Liu, Q.; Che, T.; Chen, E.; Yan, G.; et al. Watershed allied telemetry experimental research. J. Geophys. Res. Space Phys. 2009, 114, 1483-1499. [CrossRef] 
60. Wang, Z.Y.; Yang, B.; Deslauriers, A.; Bräuning, A. Intra-annual stem radial increment response of Qilian juniper to temperature and precipitation along an altitudinal gradient in northwestern China. Trees 2015, 29, 25-34. [CrossRef]

61. Qi, S.; Luo, F. Environmental degradation problems in the Heihe River Basin, northwest China. Water Environ. J. 2007, 21, 142-148. [CrossRef]

62. Chen, L.H.; Qu, Y.G. Rational Development and Utilization on Water and Soil Resources in Hexi Region; Science Pres: Beijing, China, 1992.

63. Ge, Y.; Wang, J.; Heuvelink, G.; Jin, R.; Li, X. Sampling design optimization of a wireless sensor network for monitoring ecohydrological processes in the Babao River basin, China. Int. J. Geogr. Inf. Sci. 2014, 29, 92-110. [CrossRef]

64. Stroud, P.D. A recursive exponential filter for time-sensitive data. Los Alamos Natl. Lab. Tech. Rep. 1999, 131. Available online: https://www.researchgate.net/profile/Phillip-Stroud/publication/242230998_A_Recursive_Exponential_Filter_For_ Time-Sensitive_Data/links/00b49538f4fa1be826000000/A-Recursive-Exponential-Filter-For-Time-Sensitive-Data.pdf (accessed on 8 August 2021).

65. Parisouj, P.; Mohebzadeh, H.; Lee, T. Employing machine learning algorithms for streamflow prediction: A case study of four river basins with different climatic zones in the United States. Water Resour. Manag. 2020, 34, 4113-4131. [CrossRef]

66. Lin, H.-T.; Lin, C.-J.; Weng, C.-H. A note on Platt's probabilistic outputs for support vector machines. Mach. Learn. 2007, 68, 267-276. [CrossRef]

67. Belayneh, A.; Adamowski, J.; Khalil, B.; Ozga-Zielinski, B. Long-term SPI drought forecasting in the Awash River Basin in Ethiopia using wavelet neural network and wavelet support vector regression models. J. Hydrol. 2014, 508, 418-429. [CrossRef]

68. Yoon, H.; Jun, S.-C.; Hyun, Y.; Bae, G.-O.; Lee, K.-K. A comparative study of artificial neural networks and support vector machines for predicting groundwater levels in a coastal aquifer. J. Hydrol. 2011, 396, 128-138. [CrossRef]

69. Kalra, A.; Ahmad, S.; Nayak, A. Increasing streamflow forecast lead time for snowmelt-driven catchment based on large-scale climate patterns. Adv. Water Resour. 2013, 53, 150-162. [CrossRef]

70. Yu, P.-S.; Yang, T.-C.; Chen, S.-Y.; Kuo, C.-M.; Tseng, H.-W. Comparison of random forests and support vector machine for real-time radar-derived rainfall forecasting. J. Hydrol. 2017, 552, 92-104. [CrossRef]

71. Lin, J.-Y.; Cheng, C.-T.; Chau, K.W. Using support vector machines for long-term discharge prediction. Hydrol. Sci. J. 2006, 51, 599-612. [CrossRef]

72. Yu, X.; Liong, S.-Y. Forecasting of hydrologic time series with ridge regression in feature space. J. Hydrol. 2007, 332, 290-302. [CrossRef]

73. Wu, K.-P.; Wang, S.-D. Choosing the kernel parameters for support vector machines by the inter-cluster distance in the feature space. Pattern Recognit. 2009, 42, 710-717. [CrossRef]

74. Barzegar, R.; Moghaddam, A.A.; Adamowski, J.; Fijani, E. Comparison of machine learning models for predicting fluoride contamination in groundwater. Stoch. Environ. Res. Risk Assess. 2016, 31, 2705-2718. [CrossRef]

75. Edelson, G.; Saffuri, H.; Vigder, F.; Obid, E.; Nudelman, A. Case reports: Unusual lateral clavicle fracture dislocation. Clin. Orthop. Relat. Res. 2005, 439, 274-279. [CrossRef]

76. Chai, S.-S.; Walker, J.P.; Makarynskyy, O.; Kuhn, M.; Veenendaal, B.; West, G. Use of soil moisture variability in artificial neural network retrieval of soil moisture. Remote Sens. 2009, 2, 166-190. [CrossRef]

77. Tabari, H.; Sabziparvar, A.-A.; Ahmadi, M. Comparison of artificial neural network and multivariate linear regression methods for estimation of daily soil temperature in an arid region. Theor. Appl. Clim. 2010, 110, 135-142. [CrossRef]

78. Pandey, A.; Prassad, R.; Srivasatava, J.K.; Pandey, S.N. Retrieval of soil moisture by artificial neural network using X-band ground based data. Russ. Agric. Sci. 2012, 38, 230-233. [CrossRef]

79. Dai, F.; Zhou, Q.; Lv, Z.; Wang, X.; Liu, G. Spatial prediction of soil organic matter content integrating artificial neural network and ordinary kriging in Tibetan Plateau. Ecol. Indic. 2014, 45, 184-194. [CrossRef]

80. Lin, G.-F.; Chen, L.-H. A spatial interpolation method based on radial basis function networks incorporating a semivariogram model. J. Hydrol. 2004, 288, 288-298. [CrossRef]

81. Gautam, R.; Panigrahi, S.; Franzen, D.; Sims, A. Residual soil nitrate prediction from imagery and non-imagery information using neural network technique. Biosyst. Eng. 2011, 110, 20-28. [CrossRef]

82. Moody, J.; Darken, C.J. Fast learning in networks of locally-tuned processing units. Neural Comput. 1989, 1, 281-294. [CrossRef]

83. Peternele, W.S.; Winkler-Hechenleitner, A.A.; Pineda, E.A.G. Adsorption of $\mathrm{Cd}(\mathrm{II})$ and $\mathrm{Pb}(\mathrm{II})$ onto functionalized formic lignin from sugar cane bagasse. Bioresour. Technol. 1999, 68, 95-100. [CrossRef]

84. Haykin, S. Neural Networks: A Comprehensive Foundation; IEEE Press: New York, NY, USA, 1994.

85. LeGates, D.R.; McCabe, G.J. Evaluating the use of "goodness-of-fit" measures in hydrologic and hydroclimatic model validation. Water Resour. Res. 1999, 35, 233-241. [CrossRef]

86. Zhang, L.; Jin, X.; He, C.; Zhang, B.; Zhang, X.; Li, J.; Zhao, C.; Tian, J.; Demarchi, C. Comparison of SWAT and DLBRM for hydrological modeling of a mountainous watershed in arid northwest China. J. Hydrol. Eng. 2016, 21, 04016007. [CrossRef]

87. Krause, P.; Boyle, D.P.; Bäse, F. Comparison of different efficiency criteria for hydrological model assessment. Adv. Geosci. 2005, 5, 89-97. [CrossRef]

88. Yuan, S.; Quiring, S.M. Comparison of three methods of interpolating soil moisture in Oklahoma. Int. J. Clim. 2016, 37, 987-997. [CrossRef] 
89. Wang, H.; Xu, X. Determination of spread constant in RBF neural network by genetic algorithm. Int. J. Adv. Comput. Technol. 2013, 5, 719-726. [CrossRef]

90. Wu, D.; Wang, T.; Di, C.; Wang, L.; Chen, X. Investigation of controls on the regional soil moisture spatiotemporal patterns across different climate zones. Sci. Total Environ. 2020, 726, 138214. [CrossRef] [PubMed]

91. Engstrom, R.; Hope, A.; Kwon, H.; Stow, D. The relationship between soil moisture and NDVI near barrow, Alaska. Phys. Geogr. 2008, 29, 38-53. [CrossRef]

92. Gu, Y.; Hunt, E.; Wardlow, B.; Basara, J.; Brown, J.; Verdin, J.P. Evaluation of MODIS NDVI and NDWI for vegetation drought monitoring using Oklahoma Mesonet soil moisture data. Geophys. Res. Lett. 2008, 35. [CrossRef]

93. Swenson, S.C.; Lawrence, D.; Lee, H. Improved simulation of the terrestrial hydrological cycle in permafrost regions by the community land model. J. Adv. Model. Earth Syst. 2012, 4. [CrossRef]

94. Zhang, Q.; Wei, W.; Chen, L.; Yang, L.; Luo, Y.; Cai, A. Plant traits in influencing soil moisture in semiarid grasslands of the Loess Plateau, China. Sci. Total Environ. 2020, 718, 137355. [CrossRef]

95. Zhu, B.; Xie, X.; Meng, S.; Lu, C.; Yao, Y. Sensitivity of soil moisture to precipitation and temperature over China: Present state and future projection. Sci. Total Environ. 2019, 705, 135774. [CrossRef]

96. Niu, G.-Y.; Yang, Z.-L. Effects of frozen soil on snowmelt runoff and soil water storage at a continental scale. J. Hydrometeorol. 2006, 7, 937-952. [CrossRef]

97. Niu, Y.; An, J. Response relationship between the seasonal freezing-thawing process of soil and spatial factor changes in the Dayekou basin of the Qilian Mountains. Open J. Ecol. 2018, 8, 417-431. [CrossRef]

98. Pittman, F.; Mohammed, A.; Cey, E. Effects of antecedent moisture and macroporosity on infiltration and water flow in frozen soil. Hydrol. Process. 2019, 34, 795-809. [CrossRef]

99. Wong, W.-T.; Hsu, S.-H. Application of SVM and ANN for image retrieval. Eur. J. Oper. Res. 2006, 173, 938-950. [CrossRef]

100. Aggarwal, S.K.; Goel, A.; Singh, V.P. Stage and discharge forecasting by SVM and ANN techniques. Water Resour. Manag. 2012, 26, 3705-3724. [CrossRef]

101. Lin, H.; Kogelmann, W.; Walker, C.; Bruns, M. Soil moisture patterns in a forested catchment: A hydropedological perspective. Geoderma 2006, 131, 345-368. [CrossRef]

102. Li, J.; Zhang, L.; He, C.; Zhao, C. A comparison of Markov chain random field and ordinary kriging methods for calculating soil texture in a mountainous watershed, northwest China. Sustainability 2018, 10, 2819. [CrossRef] 